agencies which apparently go on in nature in the formation of manganese deposits.

Thus far, however, no regular association of lead with the oxidized manganese minerals has been noted in the field, so far as the writer is aware.

Madison, Wis.

[From the Department of Chemistry, Princeton University.]

\title{
THE USE OF HYDROFLUORIC ACID IN THE SEPARATION OF SOME HEAVY METALS FROM TIN, ANTIMONY, TUNG- STEN, AND MOLYBDENUM, BY MEANS OF THE ELECTRIC CURRENT.
}

By LeRoy W. McCay and N. Howell Furman.

Received Jantuary 22, 1916.

About a year ago one of us (M.) showed that from a nitrohydrofluoric acid solution of copper, lead, tin, and antimony, the last two metals being in the higher state of oxidation, the electric current precipitates the copper and lead only, the former at the cathode, the latter as the peroxide at the anode. ${ }^{1}$ It was stated then that, under. similar conditions, silver and mercury can be separated from tin and antimony. Considerable experimental work has convinced $u$ s that the separation of silver and mercury from tin and antimony is as complete and their subsequent determination as exact as was observed in the case of copper and lead. The silver deposits contain no weighable amounts of platinum, which fact we attribute to the very weak currents necessarily employed in order to obtain compact silver deposits. The mercury deposits, however, usually contain a little platinum, as had already been noted in the case of copper deposited from nitrohydrofluoric acid solutions. ${ }^{2}$ The amount found is variable, but seems to increase with the quantities of tin and hydrofluoric acid present, and with the time during which the current acts. When the current strength was as high as $3 \mathrm{~A}$., and a Classen rotating anode was employed, the amount of platinum found in the mercury deposits was about $0.0005 \mathrm{~g} . ;$ in one case $0.0007 \mathrm{~g}$. On treating the deposits with nitric acid the platinum remains in the form of a black powder, or dark and very thin film, and can be rapidly and accurately determined, and the necessary correction made.

Since nitrohydrofluoric acid solutions of tungstic and molybdic acids behave toward the current like those of stannic and antimonic acids, copper, lead, silver and mercury can be separated from tungstic and molybdic as well as from mixtures of stannic, antimonic, tungstic and molybdic acids. The results for silver, copper and mercury are very satisfactory.

\footnotetext{
? THIS JOURNAL, 36, 2375 (1914).

Lanc. it.
} 
The lead peroxide deposited from nitrohydrofluoric acid solutions always weighs more than when precipitated from nitric acid solutions containing no hydrogen fluoride. The excess in weight is from $\mathrm{I}-4 \mathrm{mg}$. The error can be eliminated, and results obtained equal almost in accuracy to those arrived at when lead is determined as the peroxide in nitric acid solutions alone, by proceeding as follows:

After removing the liquid over a deposit and washing it, water containing the necessary amount of nitric acid is poured into the dish until the deposit is just covered, and the current is reversed. In a few minutes solution is complete, the current is once more reversed and the lead reprecipitated as the peroxide. Since, however, it is a well-established fact that even when lead is deposited as the peroxide from nitric acid solutions alone the calculated results are apt to be high, we have found it best, when a high degree of accuracy is desired, either to dissolve the peroxide in a few cubic centimeters of dilute nitric acid containing a little pure hydrogen peroxide, evaporate the solution to dryness in a porcelain crucible, ignite the residue and weigh the lead as oxide, or to convert the nitrate so obtained into the sulfate, the latter being collected and ignited in a Brunck or Neubauer crucible placed in a larger one of porcelain. We have succeeded in detecting fluorine in the lead peroxide deposited from nitrohydrofluoric acid solutions. No quantitative determinations of the fluorine have thus far been made, but the device employed in testing for the element has yielded such satisfactory results that we are assured it is not water alone, but fluorine in addition, which occasions the overweights of the lead peroxide.

The metals and other substances employed in our work were the best furnished by a well-known German firm. The copper, silver, tin, antimony, and lead nitrate had already been examined and found to be practically free from impurities. The mercury was purified by letting it fall in a very thin stream through a long column of dilute nitric acid. It was then distilled three times. The tungstic and molybdic anhydrides were thoroughly digested in boiling concentrated nitric acid, the acid was almost entirely removed by evaporation, the residues were taken up with water, filtered off, washed with nitric acid water and dried at about $250^{\circ}$. No traces of the presence of any heavy metals could be detected in these preparations.

Standard solutions of some of these materials were prepared and convenient amounts pipetted out as required. The necessary solutions of tin and antimony were always obtained by dissolving known weights in a little warm nitrohydrofluoric acid in a platinum dish covered with a piece of platinum foil. When a solution contained antimony, that portion remaining in the lower state of oxidation was converted into the 
higher by means of a slight excess of potassium bichromate. ${ }^{1}$ The solutions so prepared were then diluted to about $100 \mathrm{cc}$. and electrolyzed. During the passage of the current the platinum dishes were covered with split clock glasses heavily paraffined, or with pieces of hard rubber shaped like clock glasses and provided with a narrow slit extending from the center to the circumference. When relatively high amperages were used and the anode was rotated, a cover of thin platinum foil was substituted for the one of hard rubber or paraffined glass. This proved to be necessary, for the heat melted the paraffin, and the hot acid spray attacked the rubber. The cover was made by subjecting two semicircular pieces of freshly annealed platinum foil to considerable pressure in a concave and grooved mold. The resulting corrugations render the metal rigid, so that there is no danger of the cover losing its clock-glass shape.

The liquids over the deposits were siphoned off with a short piece of black rubber tubing, upon which the nitrohydrofluoric acid has practically no action. The washing was performed in the ordinary way, the main liquids and washings being trapped in a large ceresin beaker.

\section{Experimental.}

Separation of Silver from Tin and Antimony.-Weighed amounts of the metals were placed in an ordinary Classen dish of 125 cc. capacity, 20 cc. nitric acid (I part acid sp. gr. I. $42: 5$ parts water) and I cc. hydrofluoric acid $(48 \%$ ) were added, the dish was covered with a piece of platinum foil and the liquid very gently warmed until all was in solution. The antimony in the lower state of oxidation was then brought to the higher by means of a slight excess of potassium bichromate, the contents of the dish were diluted to Ioo cc., and the current was applied.

$\mathrm{Sb}, 0.102 \mathrm{I}$ to $0.1075 \mathrm{~g}$.; $\mathrm{Sn}, 0.2001$ to $0.209 \mathrm{I}$ g.; E. M. F., 2 volts; Time, overnight.
Current, ampere...... 0.07
0.10
0.05
0.05
0.05
Gram Ag taken......, $0.027 \mathrm{I}$
$0.021 \mathrm{x}$
0.0200
0.0175
0.0185
Gram Ag found...... 0.0267
0.0208
$0.0 \times 97$
$0.017 x$
0.0180

The deposits adhered well to the dish, but they were not bright in appearance. Better deposits were obtained by using a Winkler gauze electrode. The solutions were made in a platinum dish and then poured into a ceresin beaker.

Vol. $250 \mathrm{cc}$, containing $40 \mathrm{cc}$. I : $5 \mathrm{HNO}_{3}, 2 \mathrm{cc} .48 \% \mathrm{HF}$ and $\mathrm{Sb}, 0.2 \mathrm{II} 3$ to $0.3462 \mathrm{~g}$.; Sn, 0.2032 to 0.3098 g.; E. M. F., 2 volts; Time, overnight.
Current, ampere...... 0.05
0.03
0.03
0.03
0.03
Gram Ag taken....... 0.0190
0.0313
0.0326
0.0303
0.0321
Gram $\mathrm{Ag}$ found....... 0.0186
0.03 II
0.0323
0.0299
0.0320

One of us (F.) made the following determinations in a solution of unknown concentration as to silver. The silver was deposited on a gauze electrode and under the above conditions.

\footnotetext{
' This Journal, 36, 2376 (IgI4).
} 
$\mathrm{Sb}, 0.1997$ to $0.2032 \mathrm{~g}$; $\mathrm{Sn}, 0.1060$ to $0.1 \mathrm{I} 66 \mathrm{~g}$; E. M. F., 2 volts; Time, overnight.

Current, ampere.............. $0.05 \quad 0.03 \quad 0.03 \quad 0.03$

$\mathrm{Ag}$, taken ............... $25 \mathrm{cc}$. of soln.

Gram Ag............... $0.0323 \quad 0.0326 \quad 0.0325 \quad 0.0322$

The solution was prepared by dissolving $0.26 \mathrm{I} 6 \mathrm{~g}$. pure silver in a little nitric acid and diluting to $200 \mathrm{cc}$, so that $25 \mathrm{cc}$. $=0.0327 \mathrm{~g}$. Ag.

Separation of Mercury from Tin and Antimony. $-8.0603 \mathrm{~g}$. of pure, redistilled mercury were dissolved in about $\mathrm{I}_{5} \mathrm{cc}$. of concentrated nitric acid, and diluted to a liter. In $25 \mathrm{cc}$. portions the mercury was determined ( $\mathrm{I}$ ) in nitric acid solution alone, and (2) in nitrohydrofluoric acid. The deposits were washed with alcohol and ether, and dried in a vacuum desiccator over calcium chloride. The desiccator also contained a small vessel full of mercury.

Taken, 0.2015 g. $\mathrm{Hg}_{2} 20 \mathrm{cc}$. $\mathrm{HNO}_{3}$ (I : 5); Current, 0.5 amp.; E. M. F., 3 volts; Time, overnight; Vol., $100 \mathrm{cc}$.

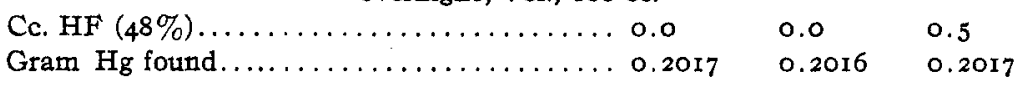

The tin and antimony were first dissolved in a platinum dish, covered with a piece of platinum foil, in $20 \mathrm{cc}$. of nitric ( $\mathrm{I}: 5$ ) and $5 \mathrm{cc}$. hydrofluoric acids, the solution being hastened by the application of a very gentle heat. The solution of mercury was then run in from a pipet, any antimony in the lower state of oxidation converted into the higher by means of a slight excess of a saturated solution of potassium bichromate, the volume of the liquid brought to about roo cc., and the current applied.

Hg taken, 0.2015 g.; Sn, 0.1863 to 0.2124 g.; Sb, 0.0857 to 0.1162 g.; E. M. F., 3 volts; Time, overnight.

$\begin{array}{llllll}\text { Current, ampere........ } & 0.50 & 0.50 & 0.45 & 0.40 & 0.50 \\ \text { Gram } \mathrm{Hg} \text { found........ } & 0.2018 & 0.2016 & 0.2014 & 0.2017 & 0.2012 \\ \text { Subtract Pt found...... } & 0.0002 & \ldots . & \ldots \ldots & 0.0001 & \ldots \ldots\end{array}$

A series of determinations in which roughly twice as much antimony and one-half as much tin were taken, yielded results fully as accurate as those just given.

Vol. Ioo cc., containing $20 \mathrm{cc}$. $\mathrm{HNO}_{2}$ (I : 5) and $5 \mathrm{cc}$. $\mathrm{HF}$ and $\mathrm{Hg}$ taken, $0.2015 \mathrm{~g}$;

$\mathrm{Sn}, 0.1005$ to $0.1087 \mathrm{~g}$; $\mathrm{Sb}, 0.1998$ to 0.2262 g.; E. M. F., 3 volts; Time, overnight.

$\begin{array}{llllll}\text { Current, ampere....... } & 0.45 & 0.45 & 0.30 & 0.25 & 0.30 \\ \text { Gram Hg found........ } & 0.2014 & 0.2013 & 0.2010 & 0.2020 & 0.2016 \\ \text { Subtract Pt found..... } & 0.0001 & 0.0001 & \ldots . & 0.0004 & \ldots\end{array}$

Equally good results for mercury were obtainied by using as little as I cc. of hydrofluoric acid.

Vol. $100 \mathrm{cc}$, containing $20 \mathrm{cc}$. $\mathrm{HNO}_{3}$ ( $\mathrm{I}: 5$ ) (except in (5) where $30 \mathrm{cc}$. were used). $\mathrm{Hg}$ taken, 0.2015 g.; $\mathrm{Sn}, 0.2004$ to $0.214 \mathrm{I} \mathrm{g.;} \mathrm{Sb,} 0.1023$ to 0.1170 g.; E. M. F., about 3 volts; Time, overnight.
Current, ampere...... 0.45
Gram $\mathrm{Hg}$ found....... 0.2014
0.45
0.40
0.2015
0.40
0.40
Subtract Pt found..... 0.0002
0.0001
0.2018
0.2016
0.2012
0.0003
0.0002 
The method was subjected to further variations in the amounts of mercury, tin, antimony, etc., the following results being obtained:

$\mathrm{Sn}, 0.2066$ to $0.4000 \mathrm{~g}$.; $\mathrm{Sb}, 0.2338$ to 0.4187 g.; Current, 0.35 amp.; E. M. F., about 3 volts; Time, overnight.

$\begin{array}{lllll}\text { C.. } \mathrm{HNO}_{3} \ldots \ldots \ldots \ldots \ldots \ldots & 40 & 35 & 40 & 50 \\ \mathrm{Cc} . \mathrm{HF}(48 \%) \ldots \ldots \ldots \ldots & 2 & 2 & 2 & 3 \\ \text { Gram } \mathrm{Hg} \text { taken.......... } 0.4030 & 0.4030 & 0.2015 & 0.2015 \\ \text { Gram } \mathrm{Hg} \text { found......... } & 0.4033 & 0.4026 & 0.2012 & 0.2013\end{array}$

The time required for the precipitation, as given in the foregoing tables, may seem unnecessarily long, and doubtless is. We found it convenient to start the runs in the evening and end them next morning. Probably all the mercury is down in six hours.

When tungstates and molybdates of the alkali metals are warmed with dilute nitric or sulfuric acids containing some hydrofluoric acid, clear and limpid solutions are obtained upon which an electric current has no reducing action. In comparison with solutions of stannic and antimonic acids containing hydrofluoric acid, the following facts, which have been established by careful experimental work, are interesting:

(I) A solution of stannic acid containing hydrofluoric acid is not reduced by the electric current, nor by warming with an excess of metallic zinc, nor by hydrogen sulfide.

(2) A solution of antimonic acid containing hydrofluoric acid is not reduced by the electric current, nor by warming with an excess of metallic zinc, but it is slightly reduced, although very sluggishly, by hydrogen sulfide, a small amount of antimony sulfide being precipitated.

(3) A solution of tungstic acid containing hydrofluoric acid is not reduced by the electric current, but it is reduced by metallic zinc. Hydrogen sulfide occasions no precipitation of tungstic sulfide. ${ }^{1}$

(4) The behavior of a solution of molybdic acid containing hydrofluoric acid toward the current and metallic zinc is, in general, similar to that shown by a corresponding one of tungstic acid. Hydrogen sulfide, however, precipitates $\mathrm{MoS}_{3}$ slowly from a hot hydrofluoric acid solution. ${ }^{1}$

Separation of Copper from Tungsten.-A nitric acid solution of electrolytic copper was used. Found: $25 \mathrm{cc}$. $=0.2005 \mathrm{~g}$. $\mathrm{Cu}$ (average of 5 well-agreeing determinations).

A solution of tungstic acid of convenient strength was prepared by dissolving $8.000 \mathrm{r}$. of purified tungstic acid in a little caustic potash, filtering the solution and diluting the filtrate to a liter. The $\mathrm{WO}_{3}$ present was determined according to the method recommended by Treadwell. ${ }^{2}$ Found: $25 \mathrm{cc} .=0.1779 \mathrm{~g} . \mathrm{WO}_{3}$ (average of 3 well-agreeing determinations).

${ }^{1}$ In regard to this, as well as some of the foregoing reactions, see A. A. Noyes, "A System of Qualitative Analysis, Including Nearly All the Metallic Elements, Part II," Tech. Quart., 17, 214 (1904); aiso MeCay, This Journal, 3I, 373 (1909).

2 Treadwell, "Quantitative Analysis," I908, p. 228. 
Vol. too cc., containing 0.2005 g. copper, 0.1779 g. tungstic acid, 5 cc. conc. $\mathrm{HNO}_{3}$, and 5 cc. HF. E. M. F., about 3 volts; Current, 0.33 amp.; Time, overnight.

$\begin{array}{lllllll}\text { Gram Cu found (cor. for Pt).... } & 0.2001 & 0.2003 & 0.2004 & 0.2006 & 0.2003 & 0.2001\end{array}$

The deposits were compact, adherent and usually salmon-pink in color. Occasionally they presented quite a burnished appearance. They always contained a little platinum, but never more than half a milligram. In the next series both the copper and the tungstic anhydride were determined. The quantities of copper, tungstic acid and of nitric and hydrofluoric acids used were the same as those just given. The current ran overnight.

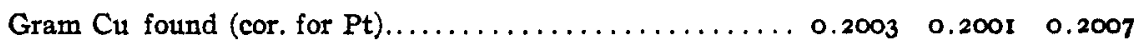
Gram $W_{3}$ found........................... $0.1776 \quad 0.17710 .1780$

In each case the liquids and washings siphoned off from a copper deposit were evaporated in a platinum dish to dryness, and the tungstic anhydride was determined according to the method recommended by Treadwell. ${ }^{1}$

Separation of Copper from Molybdenum.-The copper solution was the one we employed in the separation of the metal from tungstic acid. $25 \mathrm{cc}$. of the molybdic acid solution used in the first separations contained 0.3026 gram $\mathrm{MoO}_{3}{ }^{2}$

Vol. of solution, nitric and hydrofluoric acids, as under separation of copper from tungsten. The current ran overnight.

$0.2005 \mathrm{~g}$. $\mathrm{Cu}$ and $0.3026 \mathrm{~g}$. $\mathrm{MoO}_{3}$ taken (0.4010 $\mathrm{Cu}$ in 7 ; $0.6052 \mathrm{MoO}$ in 6); E. M. F., 2.5 to 3 volts.

$\begin{array}{llllllll}\text { Current, ampere....... } & 0.33 & 0.50 & 0.50 & 0.33 & 0.33 & 0.33 & 0.33\end{array}$

$\begin{array}{llllllll}\text { Gram } \mathrm{Cu} \text { (cor. for Pt)... } & 0.2006 & 0.2006 & 0.2006 & 0.2001 & 0.2004 & 0.1997 & 0.4012\end{array}$

All of the deposits were bright, and some of them of a burnished appearance. They were not in all cases distributed uniformly over the surface of the dish, but we noticed no tendency on the part of the metal to scale off, or separate out in spongy form. The results of some determinations of the molybdic anhydride in the liquids from which the copper had been deposited prove that the method is very satisfactory.

In all the separations of copper from molybdenum we detected platinum in the former metal. The amount, however, never exceeded half a milligram.

Separation of Copper from Tungsten and Molybdenum.-The solution electrolyzed contained in each case 0.1779 g. $\mathrm{WO}_{3}, 0.3026 \mathrm{~g} . \mathrm{MoO}_{3}$, $0.2004 \mathrm{~g}$. $\mathrm{Cu}$, the quantities of nitric and hydrofluoric acids above specified, and the volume amounted to about roo cc. Current, 0.33 ampere; E. M. F., 2.3 to 2.6 volts; ran overnight.

${ }^{1}$ Loc. cit.

2 The determinations were made according to the directions given by Treadwell. See his "Quantitative Analysis," 1908, p. 222. 


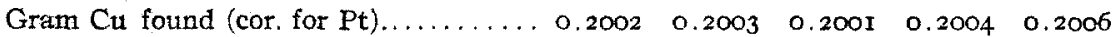

In the determinations with rotating anodes which follow, the degree of dilution of the solutions, the acid concentrations, amounts of tungstic and molybdic acids present, etc., were the same as before.

0.2010 g. Cu taken. R. P. M. of anode, 550-650.

\begin{tabular}{|c|c|c|c|c|c|}
\hline Current, amperes.............. & 4,00 & 1.75 & 1.00 & 1.75 & I. 75 \\
\hline E. M. F., volts............. & $3 \cdot 5$ & 3.0 & 3.0 & 4.0 & 4.0 \\
\hline Time, $\min . \ldots \ldots \ldots \ldots \ldots$ & 65 & 70 & 60 & 60 & 60 \\
\hline Gram Cu found (cor for $P t) \ldots$ & 0.2012 & 0.2010 & 0.2008 & 0.2009 & 0.4018 \\
\hline
\end{tabular}

The separation of lead as lead peroxide from tungstic and molybdic acids in nitrohydrofluoric acid solution is complete, but the peroxide deposited, even after it is dried to constant weight at $200^{\circ}$, is decidedly too heavy. This fact has already been referred to. In Col. I of Table I are the results of the determinations of the lead in $25 \mathrm{cc}$. portions of a standard solution of pure lead nitrate containing $6.00 \mathrm{~g}$. of the salt in a liter. In Col $\mathrm{II}$ are the weights of the peroxide found. The deposits were obtained by adding $20 \mathrm{cc}$. conc. nitric acid to $25 \mathrm{cc}$. of the solution, diluting with water to $100 \mathrm{cc}$. and submitting the liquid to the action of the current. When a rotating electrode was employed precipitation was complete in an hour. When the precipitation was carried out in the ordinary way the current was allowed to act overnight. In Col. III are the values for lead peroxide obtained after dissolving ${ }^{1}$ some of the deposits whose weights are given in Column II, in nitric acid and again electrolyzing the solutions under the same conditions, but with the addition of 5 cc. of $H F$. Col. $\mathrm{V}$ contains the weights of lead obtained by converting the two deposits whose weights are given at the end of Col. III into nitrate of lead, igniting it and weighing the oxide. In Col. IV we have the overweights in milligrams, which are due to water and fluorine in some form, and in the last column but one the times during which the current acted in precipitating the peroxide whose weights are given at the end of Col. III.

\begin{tabular}{|c|c|c|c|c|c|c|c|c|}
\hline$\underset{\text { Grann. }}{I .}$ & Gram. & Amps. & Volts. & Time. & $\begin{array}{c}\text { III. } \\
\text { Gram. }\end{array}$ & $\begin{array}{l}\text { IV. } \\
\text { Mg. }\end{array}$ & Time. & $\begin{array}{c}\text { v. } \\
\text { Gram. }\end{array}$ \\
\hline 0.0937 & 0.1082 & 4.0 & 3.5 & I hr. & $\ldots$ & $\ldots$ & $\ldots \ldots$ & $\ldots$ \\
\hline 0.0940 & o. 1085 & 0.5 & 2.0 & Overnight & 0.1097 & I. 2 & & \\
\hline 0.0942 & 0,1087 & 0.5 & 2.0 & Overnight & $\ldots$ & $\ldots$ & & \\
\hline 0.0940 & 0.1085 & 4.0 & $3 \cdot 5$ & I hr. & $\ldots$ & $\ldots$ & $\ldots .$. & \\
\hline 0.0940 & o. 1085 & 4.0 & $3 \cdot 5$ & I hr. & o. 1095 & $x .0$ & Overnight & $\cdots$ \\
\hline 0.0940 & o. 1085 & 4.0 & $3 \cdot 5$ & $\mathrm{I} \mathrm{hr}$. & 0.1100 & I. 5 & Overnight & 0.0932 \\
\hline 0.0942 & 0.1087 & 4.0 & 3.5 & I hr. & 0.1100 & I. 5 & Overnight & 0.0938 \\
\hline
\end{tabular}

Calculated : $25 \mathrm{cc}$. $=0.0938 \mathrm{~g} . \mathrm{Pb}$. Found: $25 \mathrm{cc}$. $=0.0940 \mathrm{~g}$. (average of $\mathrm{I}$ ) and 25 cc. $=0.0935$ (average of $\mathrm{V}$ ).

${ }^{1} 20 \mathrm{cc}$. conc. nitric acid are put in the dish, water is poured in until the deposit is covered, and the direction of the current is reversed. 
The lead peroxide was deposited in a Classen dish roughened by means of a sand blast. Since this dish is made the anode, and a large surface is consequently exposed to the action of oxygen, which in the presence of hydrofluoric acid has a slight action on platinum, it may lose in weight during the electrolysis, and should, therefore, be reweighed after dissolving out the peroxide with dilute nitric acid containing 2-3 cc. of pure $3 \%$ hydrogen peroxide.

The Separation of Lead from Tungsten.-The lead solution was the one employed in making the immediately preceding determinations. The tungsten solution contained in $25 \mathrm{cc}$. $0.18 \mathrm{I} 2 \mathrm{~g}$. $\mathrm{WO}_{3}$ (average of 3 wellagreeing determinations).

The results of our work are embodied in Table II. In each case 0.0938 g. $\mathrm{Pb}, 0.1812 \mathrm{~g} . \mathrm{WO}_{3}, 20 \mathrm{cc}$. conc. $\mathrm{HNO}_{3}$ and $5 \mathrm{cc}$. $\mathrm{HF}$ were present in a total volume of $100 \mathrm{cc}$. The weights of the $\mathrm{PbO}_{2}$ deposited from nitrohydrofluoric acid solution are given in the first row, and the weights of the $\mathrm{PbO}_{2}$ reprecipitated from nitric acid solution alone in the second. The third row contains the amounts of lead found, calculated from the weights as given in the second, and the fourth row the values for lead obtained by dissolving the deposits, whose weights are given in II and $I(5,6,7)$, in a little nitric acid and pure $3 \%$ hydrogen peroxide, evaporating the solutions to dryness, igniting the residue and weighing the lead oxide.

TABLE II.

Current, 0.5 amp.; E. M. F., 2.5 volts; Time, overnight.

\begin{tabular}{|c|c|c|c|c|c|c|c|}
\hline I, gram & 0.1121 & 0.1127 & 0.1117 & o. II 25 & 0.1118 & 0.1125 & 0.1127 \\
\hline II, gram.... & 0.1079 & 0.1088 & o. 1087 & 0.1085 & & $\cdots$ & \\
\hline III, gram. & 0.0934 & 0.0943 & 0.0942 & 0.0940 & $\ldots$ & $\ldots$ & \\
\hline IV, gram . . & 0.0935 & $0.094 \mathrm{I}$ & $0.094 \mathrm{I}$ & $\ldots$ & 0.0942 & $0.094 I$ & 0.0940 \\
\hline
\end{tabular}

It will be observed that the weights of the deposits in the first row are from 3-4 mg. in excess of what they are in the second. The overweights are, as has been already said, due partly at least to fluorine.

In the next series of determinations both lead and tungstic acid were estimated. In each case $25 \mathrm{cc}$. of the lead $(0.0938 \mathrm{~g} . \mathrm{Pb})$ and of the tungstic acid solutions $\left(0.1812 \mathrm{~g} . \mathrm{WO}_{3}\right)$ were pipetted into a weighed platinum dish, $5 \mathrm{cc}$. of hydrofluoric and $20 \mathrm{cc}$. of concentrated nitric acids were added, the liquid was diluted to about $100 \mathrm{cc}$. and the current applied overnight $(0.5 \mathrm{~A}$. and at $2.5 \mathrm{~V}$.). Since dilute nitrohydrofluoric acid attacks lead peroxide quite slowly, the liquid above the deposits was not siphoned off but poured off into a large ceresin beaker immediately after the current had been broken. ${ }^{1}$ The peroxide was then washed as rapidly as possible with small amounts of water. After removing the hydrofluoric acid by evaporating the solution with conc. nitric acid in platinum,

1 This Journal, 36, 2380. 
the tungstic anhydride was determined as before. The lead peroxide was dissolved and redeposited.

$\begin{array}{llllll}\text { Gram } \mathrm{Pb} \text { found..................... } & 0.0937 & 0.0939 & 0.0948 & 0.0943 \\ \text { Gram } \mathrm{WO}_{3} \text { found.............. } & 0.1797 & 0.1815 & 0.1806 & 0.1805\end{array}$

The Separation of Lead from Molybdenum.-The molybdic acid solutions used in the previous work were here employed, $0.3026 \mathrm{~g} . \mathrm{MoO}_{3}$ being present, and other conditions as in the preceding. The lead was determined as oxide or sulfate
Gram $\mathrm{PbO}_{2}$ found.... 0.1106
Gram $\mathrm{Pb}$ found..... 0.0933
0.1106
0.1103
0.1107
0.1115
$0 . \operatorname{IIr} 4$
0.0935
0.0933
0.0933
0.0934
0.0935

The fact that, in the separation of copper and mercury from tin, antimony, tungsten and molybdenum, small amounts of platinum are precipitated along with the former metals, is paralleled in these lead separations by the fact that the cathode gains steadily in weight. The deposit is undoubtedly platinum, for it is insoluble in all the ordinary solvents. Moreover, if such a discolored electrode be used in a copper or mercury determination it gradually brightens and sometimes the metal deposited will contain a milligram of platinum. The following are five successive gains of the cathode employed in the last series of separations:

$0.0002 ; 0.0002 ; 0.0002 ; 0.0003 ; 0.0002=0.001 \mathrm{Ig}$.

We also made some determinations of the molybdenum present in the liquid from which the lead had been removed. The liquid was not siphoned off but poured off into a large ceresin beaker the instant the current was broken. Calculated, $0.0939 \mathrm{~g} . \mathrm{Pb}$ and $0.2245 \mathrm{~g} . \mathrm{MoO}_{3}$.
Gram $\mathrm{Pb}$ found............. 0.0939
$0.094 \mathrm{I}$
0.0933
Gram $\mathrm{MoO}_{3}$ found........... 0.2253
0.2244
0.2238

The lead was weighed as $\mathrm{PbO}_{2}$ after solution and redeposition.

The Separation of Lead from Tungsten and Molybdenum.--The method of procedure, conditions, etc., will be evident from what has gone before. The lead was determined by converting the peroxide into the sulfate. The weights of the $\mathrm{PbO}_{2}$ deposits, as well as the overweights, are given for the purpose of comparison. 0.0939 g. Pb; 0.1812 g. $\mathrm{WO}_{3} ; 0.3026$ g. $\mathrm{MoO}_{8}$ taken.

$\begin{array}{llllll}\text { Gram } \mathrm{Pb} \text { found........... } & 0.0943 & 0.0939 & 0.0932 & 0.0939 & 0.0946 \\ \text { Gram } \mathrm{PbO}_{2} \text { found......... } & 0.1113 & 0.112 \mathrm{I} & 0.113 \mathrm{I} & 0.1116 & 0.1116 \\ \text { Milligrams overweight..... } 2.9 & 3.7 & 4.7 & 3.2 & 3.2\end{array}$

It will be noted that when tungstic and molybdic acids are present, the overweights are considerably greater than they are when the peroxide is precipitated from nitrohydrofluoric acid solutions alone. The overweights are, as we have already stated, due partly, possibly almost wholly, to fluorine in some form. Peroxide of lead is decomposed with difficulty by concentrated sulfuric acid, but on long heating to a point just below that at which the acid begins to fume the transformation into 
the sulfate is almost complete. The residue is never white, but of a pink color. In testing for fluorine we have made use of a device which dispenses with waxed or paraffined watch glasses. The peroxide which has been deposited in a smooth platinum dish, from which most of it can generally be easily removed, is, after a thorough washing, and drying at $200^{\circ}$, ground to an impalpable powder in a small agate mortar, and a convenient amount is weighed out in an ordinary platinum crucible. A little concentrated sulfuric acid is added and the mass well stirred with a small platinum spatula. A platinum Gooch, with a mouth of which the diameter is somewhat less than that of the other crucible, is inverted and forced gently into the lower crucible until it remains in place and upright. A fairly tight joint between the two is thus obtained. Over the holes in the Gooch is placed a small glass cover, such as is employed in microscopical work, and the bottom of the lower crucible is heated with a tiny flame to a temperature barely high enough to make the sulfuric acid fume. At the end of half an hour the cover is removed, washed and dried. All the samples of lead peroxide deposited from nitrohydrofluoric acid solution which we examined in this way (we used from $0.1-0.3 \mathrm{~g}$. for a test) gave us fine reactions for fluorine. In most cases perfect patterns of the perforated surface on which the glass cover rests were obtained. It is hardly necessary to state that we convinced ourselves by numerous blank experiments that the acid alone, as well as mixed with peroxide free from fluorine, had no action on the glass. The test is exceedingly delicate, for by means of it we have had no trouble in detecting $0.000 \mathrm{~g}$. of fluorine. If a platinum Gooch is not at hand, cover the crucible containing the mixture of fluoride and concentrated sulfuric acid with a piece of platinum foil, in which a number of small holes have been pierced with a needle, press it down firmly and place the glass slip over the holes. ${ }^{1}$

Separation of Mercury from Tungsten.-The following determinations of mercury in the presence of tungstic acid show that the method is very satisfactory. Everything worked well from start to finish, and the appearance of the mercury deposits left nothing to be desired. The solution in each case, when ready for electrolysis, amounted to from Ioo- I Io cc., and contained o. $1779 \mathrm{~g}$. $\mathrm{WO}_{3}, 5 \mathrm{cc}$. conc. $\mathrm{HNO}_{3}$, and $5 \mathrm{cc}$. $48 \% \mathrm{HF}$. The current ran overnight.

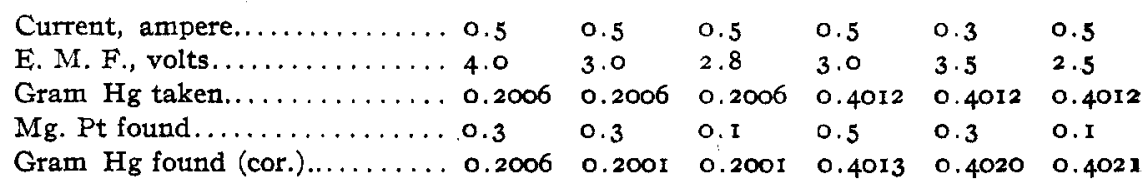

1 This modification of the usual method for testing for fluorine is not mentioned in the treatises of Fresenius, Classen and Treadwell. We had supposed that the device was new, but find that it was suggested by $\mathbf{F}$. von Kobell in 1864 . See J. prakt. Chew., 92, 389 (I864). 
Separation of Mercury from Molybdenum.-Our first results were unsatisfactory. The mercury deposits were gray, spotted here and there with black specks, and from 2-6 mg. higher than they should have been. The solutions too, which were originally colorless, became in the course of time faintly greenish yellow, and the platinum dish employed was attacked to an unusual degree. The losses in weight of the dish were very irregular, varying from $2-7 \mathrm{mg}$. We have found, however, that by employing a relatively low electromotive force (less than 2 volts) the separation is complete and satisfactory, the only irregularity being the loss in weight suffered by the dish when the mercury deposits were dissolved in nitric acid. The weight of the anode remains practically constant, and this was our experience in separating silver from tin and antimony, where a small electromotive force was employed.

The determinations of mercury which follow were made with a solution containing $0.2083 \mathrm{~g}$. mercury per $25 \mathrm{cc}$. Barring the low electromotive force the conditions were about the same as those generally observed.

0.2032 to 0.2222 g. MoOs taken; Current, O.I amp.; E. M. F., I.4 to 1.6 volts; Time, overnight.

$\begin{array}{llllllll}\text { Gram Hg found } \ldots \ldots \ldots & 0.2079 & 0.2077 & 0.2078 & 0.2080 & 0.2083 & 0.2086 & 0.2086 \\ \mathrm{Mg} . \text { anode loss......... } & 0.3 & 0.1 & 0.1 & 0.3 & 0.1 & 0.0 & 0.0\end{array}$

Cold nitric acid of I. $26 \mathrm{sp}$. gr. dissolves quite readily the bright mercury deposits, but a gray film always remains on the dish, which disappears slowly but completely on warming the acid. It dissolves more rapidly in concentrated nitric acid. The cold dilute nitric acid solution contains most of the mercury and a small amount of platinum, while the solution of the gray film, in addition to the rest of the mercury, contains a comparatively large amount of platinum. When such a solution, after dialysis, is evaporated to dryness in a porcelain crucible and the residue strongly ignited, a small amount of a black substance remains which dissolves only in aqua regia, and gives with stannous chloride fine reactions for platinum. The loss in weight of the dish amounted to 2.5 $\mathrm{mg}$., which is the average of a number of determinations. That the dissolved platinum can be recovered will be evident from the following results. They correspond to the determinations of mercury given in the preceding tabulation.

$\begin{array}{lllllllll}\text { Dish lost, mg......... } \ldots & 1.2 & 0.9 & 2.4 & 4.5 & 1.9 & 1.8 & 3.4 & 1.5 \\ \mathrm{Pt} \text { in } \mathrm{I}: \mathrm{I} \mathrm{HNO}_{3} \ldots \ldots \ldots & \ldots & \ldots & \ldots & \ldots & \ldots & 0.6 & 0.6 & \ldots \\ \mathrm{Pt} \text { in conc. } \mathrm{HNO}_{3} \ldots \ldots \ldots & \ldots .3 & 1.2 & 2.4 & 4.5 & 2.6 & 1.3 & 3.2 & 1.5\end{array}$

Just what role is here played by the molybdenum we are unable to say. It certainly accelerates the rate at which the dish is attacked, and conditions the formation of the gray film. The usual loss in weight of a dish when mercury is deposited from its dilute nitric acid solution alone is never over $0.5 \mathrm{mg}$. The molybdic acid employed had, as said, been 
digested for a long time with boiling conc. nitric acid. It dissolved in ammonium hydroxide. without leaving any residue, and, tested according to the directions given by Merck, ${ }^{1}$ gave no reactions for heavy metals.

Separation of Mercury from Tin, Antimony, Tungsten and Molybdenum.-Very satisfactory results were obtained by one of us (F.) in determining the amount of mercury present in a solution of unknown concentration.

Vol. soln., IOO-I Io cc. containing approx. $0.2 \mathrm{~g}$. Sn, 0.1 to $0.25 \mathrm{~g}$. Sb, $0.2 \mathrm{~g}$. $\mathrm{WO}_{3}$ and 0.2 to $0.26 \mathrm{~g} . \mathrm{MoO}_{3}$; Current, O.I amp.; E. M. F., I.4-I.5 v.; Time, overnight.

(Double quantities of $\mathrm{Hg}$ were taken in last two determinations.)

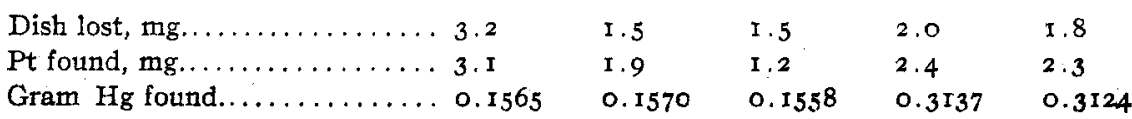
Average for $25 \mathrm{cc}$. $=0.1565 \mathrm{~g}$. Should be 0:1565. Weight of anode remained constant.

Separation of Silver from Tin, Antimony, Tungsten and Molybdenum. - The conditions here observed were very similar to those described in connection with the separation of silver from tin and antimony, but the solutions were held in a ceresin beaker and the metal was deposited on a Winkler gauze electrode.

Vol. of soln., $250 \mathrm{cc}$. containing $0.020 \mathrm{~g}$. $\mathrm{Ag}$, o to $0.2 \mathrm{~g}$. $\mathrm{Sn}$, o to $0.1 \mathrm{~g}$. Sb, o to $0.14 \mathrm{~g}$. $\mathrm{WO}_{3}$ and 0.1 to $0.22 \mathrm{~g}$. $\mathrm{MoO}_{3}$; Current, 0.05 amp.; E. M. F., I volt; Time, overnight. $\begin{array}{lllllllllllllll}\text { Gram } \mathrm{Ag} \text { found...... } & 0.0198 & 0.0197 & 0.0200 & 0.0199 & 0.0198 & 0.0200\end{array}$ Wt. of anode constant as result of low E. M. F. No correction for Pt.

Silver can be separated from all the above-mentioned metals in one hour by using a rotating anode.

Vol. of soln., $250 \mathrm{cc}$. containing approx. $0.2 \mathrm{~g}$. Sb, $\mathrm{Sn}, \mathrm{WO}_{3}$, and $\mathrm{MoO}_{3}$ each. Current, $0.5-0.75$ amp.; E. M. F., 2.2 to 2.75 v.; R. P. M., 500-550; Time, 40 minutes.
Gram Ag taken............ 0.0375
0.0375
0.0375
0.0200
0.0200
Gram Ag found............ 0.0380
0.0379
0.0373
0.0197
0.0202

The silver deposits were light gray, compact, and firmly adherent. The anode used was a long platinum-iridium spatula, and was not attacked during the series of determinations, as its weight was found to remain constant. Hence no corrections were necessary.

\section{Additional Facts on the Separation of Copper from Other Metals by} the HF Method.-Copper can be separated from tin, antimony, tungsten and molybdenum, when all of these metals are present in nitrohydrofluoric acid solution, observing the usual conditions of voltage, dilution, etc. Further, if a voltage of less than 2.0 be used, copper can be quantitatively separated from arsenic, or arsenic and the four elements mentioned.

These facts will be evident from the results given in the following tabulation. The procedure will be obvious from preceding descriptions.

1 "Chemical Reagents," Merck \& Co., rgr4. 
$0.2010 \mathrm{~g}$. Cu taken and o to $0.2 \mathrm{~g}$. $\mathrm{Sn}$, o to $0.2 \mathrm{~g}$. Sb, o to $0.2 \mathrm{~g}$. $\mathrm{WO}_{3}, \circ$ to $0.22 \mathrm{~g} . \mathrm{MoO}_{3}$, 0 to $0.5 \mathrm{~g} . \mathrm{KH}_{2} \mathrm{AsO}_{4}$.

$\begin{array}{lllllllll}\text { Current, ampere..... } & 0.25 & 0.2 & 0.1 & 0.1 & 0.1 & 0.05 & 0.1 & 0.1\end{array}$

$\begin{array}{lllllllll}\text { E...M. F., volts....... } & 2.4 & 2.4 & 1.4 & 1.4 & 1.4 & 1.3 & 1.7 & \text { I.7 }\end{array}$

Gram $\mathrm{Cu}$ found....... $0.2013 \quad 0.2012 \quad 0.2015 \quad 0.20090 .201$ I 0.20110 .20110 .2010

The first two results given have the copper value corrected for platinum present. In the last six determinations no correction is made, for although in some cases a faint qualitative reaction for platinum was obtained, in no case was there a weighable amount deposited with the copper.

As an example of the immediate practical application of the HF method for separating copper from $\mathrm{W}, \mathrm{Mo}$, etc., we offer the following determinations of the copper in an alloy (No. II7) prepared by S. W. Parr. ${ }^{1} \mathrm{Mr}$. S. F. Cox was kind enough to furnish us with a sample of the alloy. According to the analysis of Rowland and Braley, the alloy contains $6.42 \% \mathrm{Cu}$.

We find: $6.37 ; 6.59 ; 6.44 ;$ average, 6.46 .

A number of interesting theoretical matters have come up in connection with the use of hydrofluoric acid in electrochemical analysis. Some of these are being investigated.

Princeiton, N. J.

NOTE.

Note on a Convenient Dip Electrode. - In the determination of the conductivity value ${ }^{2}$ and of the volumetric lead number ${ }^{3}$ of maple syrups, conductivity cells with very rigid electrodes are required, so that the distance between the electrodes may not be altered in stirring the somewhat viscous diluted syrup. The cell recommended by Snell ${ }^{4}$ is unsuitable for the volumetric lead determination, inasmuch as the precipitate settles upon the horizontal electrodes. Its unprotected electrodes are also subject to accidental displacement.

The small dip electrode ${ }^{5}$ used in beginning the work on the determination of the volumetric lead number of maple syrup, also proved to be unsatisfactory, since the electrodes were much too small and were also subject to displacement when the diluted syrups were stirred.

The writer overcame these disadvantages by designing the electrode shown in the illustration. It consists of a hard glass cylinder $6.5 \mathrm{~cm}$. high by $3.7 \mathrm{~cm}$. in diameter open at both ends. One end is fitted with a vulcanite cap, B, and is fastened to the cylinder by means of set screws.

2 "An Acid-Resisting Alloy to Replace Platinum in the Construction of a Bomb Calorimeter," Ters JouRNaL, 37, 2515 (1915).

${ }^{2}$ Snell, J. Ind. Eng. Chem., 5, 740 (I913).

${ }^{3}$ Snell, MacFarlane and Van Zoeren, Ibid., 8, 24I (1916).

4 Loc. cit.

'Snell, J. Ind. Eng. Chem., 8, 144 (1916). 